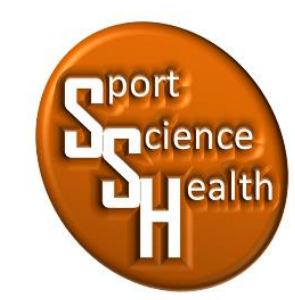

ISSN 2715-3886

\title{
Survei Sarana dan Prasarana Mata Pelajaran Pendidikan Jasmani Olahraga dan Kesehatan Tingkat SMP
}

\author{
Elsa Dwi Ratnasari ${ }^{1 \star}$, Tatok Sugiarto², Gema Fitriady ${ }^{3}$ \\ 1,2,3 Jurusan Pendidikan Jasmani, Kesehatan dan Rekreasi, Fakultas IImu Keolahragaan, \\ Universitas Negeri Malang, Jalan Semarang No 5, Malang, Jawa Timur, 65145, Indonesia \\ *Penulis koresponden: elsadwiratna57@gmail.com, 082139969005
}

Artikel diterima: 14 Januari 2020; direvisi: 18 November 2020; disetujui: 23 November 2020

\begin{abstract}
This study aims to determine the number and feasibility of physical education facilities and infrastructure for sports and health at the junior high school level in Pasuruan City. It is hoped that this research can provide input to certain parties, such as schools and the local education office. This research is a type of survey research using descriptive statistical analysis techniques. The data collection process in this study consisted of two stages, namely 1) the preparation stage and 2) the implementation stage. Furthermore, based on the research, it was obtained that the percentage of the overall facilities included large ball game equipment $83.84 \%$ in the feasible category, $91.24 \%$ athletic equipment in the feasible category, the gymnastics equipment using $28.28 \%$ in the less feasible category, $21.21 \%$ floor gym equipment not feasible, and aerobic equipment $9.60 \%$ category is not feasible. For infrastructure, the overall percentage is $85.71 \%$ with the feasible category.
\end{abstract}

Keyword: surveys, facilities and infrastructure, physical education, sports and health

\begin{abstract}
Abstrak: Penelitian ini bertujuan untuk mengetahui jumlah dan kelayakan sarana dan prasarana pendidikan jasmani olahraga dan kesehatan tingkat Sekolah Menengah Pertama di Kota Pasuruan. Diharapkan dengan ini penelitian dapat memberikan masukan pada pihak tertentu, seperti sekolah, dan Dinas Pendidikan setempat. Penelitian ini merupakan jenis penelitian survei dengan menggunakan teknik analisis statistik deskriptif. Adapun proses pengumpulan data pada penelitian ini terdapat dua tahap yaitu 1) tahap persiapan dan 2) tahap pelaksanaan. Selanjutnya berdasarkan penelitian diperoleh hasil persentase sarana keseluruhan meliputi peralatan permainan bola besar $83,84 \%$ kategori layak, peralatan atletik $91,24 \%$ kategori layak, peralatan senam menggunakan alat $28,28 \%$ kategori kurang layak, peralatan senam lantai 21,21\% tidak layak, dan peralatan aerobik 9,60\% kategori tidak layak. Untuk prasarana diperoleh hasil persentase keseluruhan yaitu 85,71\% dengan kategori layak.
\end{abstract}

Kata kunci: survei, sarana dan prasarana, pendidikan jasmani olahraga dan kesehatan

\section{PENDAHULUAN}

Pendidikan merupakan faktor yang sangat penting dalam kehidupan manusia. Adanya pendidikan yang baik diharapkan manusia dapat mengembangkan pengetahuan, keterampilan dan kreativitasnya. Untuk mencapai hasil yang maksimal dari pendidikan, ditentukan dalam proses pembelajaran terdiri atas rangkaian kegiatan proses belajar dan mengajar terhadap peserta didik. Pendidikan yang mencakup aspek pengetahuan, 
keterampilan dan kreativitas salah satu mata pelajaran terkait adalah pendidikan jasmani olahraga dan kesehatan.

Pendidikan jasmani, olahraga, dan kesehatan adalah bagian penting dari proses pendidikan. Artinya, pendidikan jasmani sendiri bukan hanya dekorasi atau ornamen yang ditempel pada program sekolah sebagai alat untuk membuat anak sibuk. Tetapi, pendidikan jasmani, olahraga, dan kesehatan juga merupakan bagian penting dari pendidikan. Menurut pernyataan ahli bahwa Pendidikan jasmani merupakan proses pendidikan yang memanfaatkan aktivitas jasmani yang direncanakan secara sistematik bertujuan untuk mengembangkan dan meningkatkan individu secara organik, neuromuskuler, perseptual, kognitif, dan emosional, dalam kerangka sistem pendidikan nasional (Adi \& Fathoni, 2019, 2020b, 2020a; Fathoni, 2018; Fathoni \& Fajar, 2017). Pembelajaran pendidikan jasmani olahraga dan kesehatan dapat berjalan dengan sukses dan lancar ditentukan oleh beberapa unsur antara lain peran tenaga pendidik, peserta didik, sarana dan prasarana, dan lingkungan yang juga mendukung.

Peran tenaga pendidik merupakan unsur yang menentukan keberhasilan proses pembelajaran. Sebagaimana dijelaskan dalam Peraturan Menteri Pendidikan Nasional Republik Indonesia No. 19 Tahun 2017 Tentang Standar Pengelolaan Pendidikan Oleh Satuan Pendidikan Dasar dan Menengah menyatakan bahwa.

"guru melaksanakan tugas dan tanggung jawabnya sebagai agen pembelajaran yang memotivasi, memfasilitasi, mendidik, membimbing, dan melatih peserta didik sehingga menjadi manusia yang berkualitas dan mampu mengaktualisasikan potensi kemanusiaanya secara optimum. Melalui pembelajaran pendidikan jasmani, olahraga, dan kesehatan, peserta didik dapat mengembangkan seluruh potensi yang mereka miliki seperti pengetahuan, keterampilan, penalaran, serta perkembangan emosional. Peranan tenaga pendidik sangat penting untuk tercapainya hasil pembelajaran pada peserta didiknya."

Mencermati dari segi guru pendidik, tidak kalah pentingnya sarana dan prasarana juga termasuk hal yang vital dan harus ada dalam menunjang proses belajar mengajar pendidikan jasmani di sekolah. Sarana dan prasarana pendidikan dan pendayagunaan komponen-komponen yang secara langsung maupun tidak langsung menunjang proses pendidikan untuk mencapai tujuan pendidikan secara efektif dan efisien (Asseffa, Bukola, \& Ayodele, 2016; Efendi et al., 2019; Napitupulu et al., 2018). Dalam hal ini, sarana dan prasarana merupakan salah satu faktor penting penunjang pencapaian belajar peserta didik dalam proses pembelajaran agar lebih optimal. Kelengkapan sarana dan prasarana pendidikan jasmani, olahraga, dan kesehatan seperti peralatan permainan bola besar, peralatan atletik, peralatan senam menggunakan alat, peralatan senam lantai,dan peralatan aerobik, serta tempat bermain dan berolahraga harus sebanding dengan jumlah peserta didik yang ada, sehingga proses kegiatan pembelajaran berjalan dengan lancar dan sungguh ideal apabila setiap sekolah dilengkapi sarana dan prasarana yang memadai.

Keberadaan sarana dan prasarana di SMP Negeri se-Kota Pasuruan sangat kurang menunjang dalam proses pembelajaran pendidikan jasmani olahraga dan kesehatan. Karena tuntutan disetiap cabang olahraga memerlukan fasilitas berupa sarana dan prasarana yang menunjang dapat memperlancar kegiatan, agar proses belajar mengajar juga berjalan dengan baik. Tetapi dengan kenyataan yang ada sekarang cukup menyedihkan, pasalnya karena banyak tempat bermain dan berolahraga sekolah-sekolah di SMP se-Kota Pasuruan tersebut digunakan untuk membuat gedung atau kelas baru misalnya. Padahal sudah tahu dengan jelas sarana dan prasarana adalah pendukung jalannya pembelajaran pendidikan jasmani. Oleh karena itu, tenaga pendidik di sekolah dituntut untuk berinisiatif dan kreatif dalam penyampaian materi kepada peserta didik dengan sarana dan prasarana olahraga yang kurang memenuhi atau tidak layak tersebut.

Merujuk pada penelitian sebelumnya yang dilakukan oleh Khikmah (2017) tentang "Survei Sarana dan Prasarana Pendidikan Jasmani di Madrasah Tsanawiyah (MTs) se-Kecamatan Klojen Kota Malang pada Semester Ganjil Tahun 2017" mendapatkan hasil bahwa secara keseluruhan keadaan sarana dan prasarana di MTs se-Kecamatan Klojen Kota Malang adalah 38\% dan memiliki sarana pembelajaran pendidikan jasmani dalam kriteria yang kurang baik. Penelitian sebelumnya juga dilakukan oleh Krisnabayu (2019) tentang "Survei Sarana dan Prasarana Pendidikan Jasmani Olahraga dan Kesehatan SMP Negeri 6 Sinjai Selatan Kabupaten Sinjai" mendapatkan hasil bahwa secara umum jumlah sarana dan prasarana pendidikan jasmani olahraga dan kesehatan di SMP Negeri 6 Sinjai Selatan sudah cukup ideal dengan persentase 52,96\%.

Dapat diketahui jumlah Sekolah Menengah Pertama Negeri se-Kota Pasuruan terdapat 11 sekolah dengan luas daerah sekolah yang berbeda-beda, masing-masing sekolah memiliki luas, ketersediaan, kelayakan sarana dan prasarana yang juga tidak sama. Dari data observasi awal yang sudah dilakukan peneliti pada 
bulan Juli-Agustus 2018 bahwa betapa beragamnya kondisi sarana dan prasarana olahraga di Sekolah Menengah Pertama Negeri se-Kota Pasuruan. Observasi awal ini mengacu pada hasil dan penyebaran lembar angket observasi kepada guru pendidikan jasmani di sekolah, serta dokumentasi pada saat melakukan observasi di 11 sekolah tersebut.

Berdasarkan hal yang sudah dikemukakan, maka timbul permasalahan yang perlu diangkat dalam suatu penelitian yang berhubungan dengan sarana dan prasarana olahraga pada SMP Negeri di Kota Pasuruan yaitu "Survei Sarana dan Prasarana Mata Pelajaran Pendidikan Jasmani Olahraga dan Kesehatan Tingkat SMP".

\section{METODE}

Dalam penelitian, ini peneliti menggunakan metode survei dan pendekatan deskriptif kuantitatif. Alasan peneliti mengambil metode dan perlakukan ini karena tidak adanya perlakuan dalam penelitian. Ditinjau dari tujuan penelitian yaitu peneliti akan mendeskripsikan tentang bagaimana keadaan dan kelayakan sarana dan prasarana mata pelajaran pendidikan jasmani olahraga dan kesehatan di Sekolah Menengah Pertama Negeri Se-Kota Pasuruan, jumlah sarana dan prasarana yang menunjang dalam pembelajaran pendidikan jasmani olahraga dan kesehatan di sekolah tersebut. Terkait dengan penelitian survei sendiri dikemukakan oleh beberapa pernyataan dijelaskan bahwa penelitian survei adalah penelitian pengamatan yang berskala besar dilakukan pada kelompok-kelompok manusia (Adiningtyas, Tomi, \& Yudasmara, 2020; Dawud \& Hariyanto, 2020; Litardiansyah \& Hariyanto, 2020; Zulfa \& Kurniawan, 2020).

Subjek penelitian yang digunakan oleh peneliti adalah seluruh SMP Negeri di Kota Pasuruan yang keseluruhan berjumlah 11 sekolah antara lain, SMP Negeri 1, SMP Negeri 2, SMP Negeri 3, SMP Negeri 4, SMP Negeri 5, SMP Negeri 6, SMP Negeri 7, SMP Negeri 8, SMP Negeri 9, SMP Negeri 10, SMP Negeri 11 yang dilaksanakan pada bulan Juli 2018. Disebabkan karena keterbatasan tenaga, waktu, dan juga dana peneliti terpaksa membatasi banyaknya subjek penelitian dengan cara mengambil subjek penelitian disesuaikan dengan kemampuan yang ada (Kafle, 2013; Kunlasomboon, Wongwanich, \& Suwanmonkha, 2015).

Penelitian ini mengunakan jenis data yang berbentuk deskripsi dan angka yang akan dipaparkan untuk mendeskripsikan sarana dan prasarana penunjang mata pelajaran pendidikan jasmani olahraga dan kesehatan di sekolah yang dituju oleh peneliti.Sumber data yang digunakan oleh peneliti berupa data primer dan data sekunder. Data primer yang dimaksud adalah yang diperoleh peneliti langsung dari subjek penelitian berupa observasi disertai adanya dokumentasi. Data sekunder yang dimaksud adalah yang diperoleh peneliti berupa lembar observasi penelitian berbentuk form sarana dan prasarana yang diisi oleh guru pendidikan jasmani di 11 sekolah yang dituju.

Teknik mengumpulkan data yang digunakan oleh peneliti berupa observasi berbentuk form sarana dan prasarana, menyebarkan lembar observasi dan disertai dokumentasi untuk mendukung pengumpulan data. Sesuai dengan pokok bahasan tentang survei sarana dan prasarana mata pelajaran pendidikan jasmani olahraga dan kesehatan di SMP Negeri se-Kota Pasuruan, maka instrumen yang akan dipergunakan oleh peneliti berupa lembar observasi untuk guru pendidikan jasmani di sekolah yang dituju oleh peneliti. Instrumen penelitian yang disusun oleh peneliti sendiri disesuaikan dengan kebutuhan, disertai dengan dokumentasi.

Sesuai dengan tujuan penelitian maka teknik analisis data yang digunakan adalah teknik analisis data statistik deskriptif. Kriteria sarana dan prasarana akan dijumlah lalu dibandingkan kondisi nyata sarana dan prasarana pendidikan jasmani olahraga dan kesehatan di SMP Negeri se-Kota Pasuruan dengan kondisi ideal sesuai dengan standar ketentuan sarana dan prasarana dari Permendiknas Nomor 24 Tahun 2007. Selanjutnya untuk analisis data menggunakan rumus dari Sudijono (2008:43). 
Tabel 1. Skala Kategori Kelayakan (Ichsan \& Mulyani, 2018; McCusker \& Gunaydin, 2015)

\begin{tabular}{ll}
\hline Definisi & Kriteria Pencapaian \\
\hline Sangat Layak & $81 \%-100 \%$ \\
Layak & $61 \%-80 \%$ \\
Cukup Layak & $41 \%-60 \%$ \\
Kurang Layak & $21 \%-40 \%$ \\
Tidak Layak & $0 \%-20 \%$ \\
\hline
\end{tabular}

HASIL

Berdasarkan hasil penelitian yang dilakukan oleh peneliti yaitu survei sarana dan prasarana penunjang mata pelajaran pendidikan jasmani olahraga dan kesehatan Tingkat SMP Negeri Se-Kota Pasuruan dapat di deskripsikan sebagai berikut:

\section{SMP Negeri 1 Pasuruan}

Sarana keseluruhan yang dimiliki oleh SMP Negeri 1 Pasuruan meliputi bola basket berjumlah 3 , bola voli berjumlah 7 , bola sepak berjumlah 1 , memiliki tongkat estafet berjumlah 10 , meteran berjumlah 1 , memiliki bola plastik berjumlah 3 , matras berjumlah 2 , dan memiliki tape recorder berjumlah 3 . Sekolah ini mempunyai prasarana atau luas tempat bermain dan berolahraga sebesar $516 \mathrm{~m}^{2}$.

\section{SMP Negeri 2 Pasuruan}

Sarana keseluruhan yang dimiliki oleh SMP Negeri 2 Pasuruan meliputi bola basket berjumlah 3, bola voli berjumlah 2, bola sepak berjumlah 1 , memiliki tongkat estafet berjumlah 3 , meteran berjumlah 1 , alat tolak peluru berjumlah 4 , lempar cakram berjumlah 2 , lempar lembing berjumlah 8 , memiliki bola plastik berjumlah 4, matras berjumlah 2, dan memiliki tape recorder berjumlah 1 . Sekolah ini mempunyai prasarana atau luas tempat bermain dan berolahraga sebesar $970,75 \mathrm{~m}^{2}$.

\section{SMP Negeri 3 Pasuruan}

Sarana keseluruhan yang dimiliki oleh SMP Negeri 3 Pasuruan meliputi bola basket berjumlah 4, bola voli berjumlah 6 , bola sepak berjumlah 6 , memiliki tongkat estafet berjumlah 4 , tolak peluru berjumlah 2 , lempar cakram berjumlah 2, lempar lembing berjumlah 2, memiliki bola plastik berjumlah 6 , alat simpai berjumlah 2 , matras berjumlah 2, memiliki tape recorder berjumlah 1, dan memiliki kaset senam berjumlah 1 . Sekolah ini mempunyai prasarana atau luas tempat bermain dan berolahraga sebesar $154 \mathrm{~m}^{2}$.

\section{SMP Negeri 4 Pasuruan}

Sarana keseluruhan yang dimiliki oleh SMP Negeri 4 Pasuruan meliputi bola basket berjumlah 6 , bola voli berjumlah 8 , bola sepak berjumlah 4 , tongkat estafet berjumlah 11 , meteran berjumlah 2 , memiliki alat tolak peluru berjumlah 5 , lempar cakram berjumlah 4 , lempar lembing berjumlah 12 , memiliki alat simpai berjumlah 3 , matras berjumlah 6 , memiliki tape recorder berjumlah 1 , dan memiliki kaset senam berjumlah 1 . Sekolah ini mempunyai prasarana atau luas tempat bermain dan berolahraga sebesar $625 \mathrm{~m}^{2}$.

\section{SMP Negeri 5 Pasuruan}

Sarana keseluruhan yang dimiliki oleh SMP Negeri 5 Pasuruan meliputi bola basket berjumlah 10, bola voli berjumlah 7 , bola sepak berjumlah 4 , memiliki tongkat estafet berjumlah 6 , meteran berjumlah 2 , memiliki alat tolak peluru berjumlah 4 , lempar cakram berjumlah 3 , lempar lembing berjumlah 4 , memiliki bola plastik berjumlah 3 , matras berjumlah 8 , peti loncat berjumlah 2, memiliki tape recorder berjumlah 1, dan memiliki kaset senam berjumlah 2 . Sekolah ini mempunyai prasarana atau luas tempat bermain dan berolahraga sebesar $768 \mathrm{~m}^{2}$.

\section{SMP Negeri 6 Pasuruan}

Sarana keseluruhan yang dimiliki oleh SMP Negeri 6 Pasuruan meliputi bola basket berjumlah 8 , bola voli berjumlah 9 , bola sepak berjumlah 7 , memiliki tongkat estafet berjumlah 6 , meteran berjumlah 1 , memiliki alat tolak peluru berjumlah 4 , lempar cakram berjumlah 3 , lempar lembing berjumlah 5 , memiliki matras berjumlah 4, dan memiliki tape recorder berjumlah 1. Sekolah ini mempunyai prasarana atau luas tempat bermain dan berolahraga sebesar $607,5 \mathrm{~m}^{2}$. 


\section{SMP Negeri 7 Pasuruan}

Sarana keseluruhan yang dimiliki oleh SMP Negeri 7 Pasuruan meliputi bola basket berjumlah 6 , bola voli berjumlah 6 , bola sepak berjumlah 7 , memiliki tongkat estafet berjumlah 20 ,meteran berjumlah 1 , memiliki alat tolak peluru berjumlah 2, lempar cakram berjumlah 4, lempar lembing berjumlah 10, memiliki matras berjumlah 2, memiliki tape recorder berjumlah 1 , dan memiliki kaset senam berjumlah 1 . Sekolah ini mempunyai prasarana atau luas tempat bermain dan berolahraga sebesar $1059 \mathrm{~m}^{2}$.

\section{SMP Negeri 8 Pasuruan}

Sarana keseluruhan yang dimiliki oleh SMP Negeri 8 Pasuruan meliputi bola basket berjumlah 9, bola voli berjumlah 10 , bola sepak berjumlah 8 , memiliki tongkat estafet berjumlah 10 , meteran berjumlah 2 , memiliki alat tolak peluru berjumlah 3 , lempar cakram berjumlah 4 , lempar lembing berjumlah 8 , memiliki bola plastik berjumlah 3 , tali loncat berjumlah 5 , matras berjumlah 4 , memiliki tape recorder berjumlah 1 , dan memiliki kaset senam berjumlah 1 . Sekolah ini mempunyai prasarana atau luas tempat bermain dan berolahraga sebesar $1527 \mathrm{~m}^{2}$.

\section{SMP Negeri 9 Pasuruan}

Sarana keseluruhan yang dimiliki oleh SMP Negeri 9 Pasuruan meliputi bola basket berjumlah 1, bola voli berjumlah 4 , bola sepak berjumlah 3 , memiliki tongkat estafet berjumlah 10 , meteran berjumlah 1 , memiliki alat tolak peluru berjumlah 4 , lempar cakram berjumlah 4 , lempar lembing berjumlah 4 , memiliki bola plastik berjumlah 8 , matras berjumlah 4 , peti loncat berjumlah 1 , memiliki tape recorder berjumlah 1 , dan memiliki kaset senam berjumlah 1 . Sekolah ini mempunyai prasarana atau luas tempat bermain dan berolahraga sebesar $1450 \mathrm{~m}^{2}$.

\section{SMP Negeri 10 Pasuruan}

Sarana keseluruhan yang dimiliki oleh SMP Negeri 10 Pasuruan meliputi bola basket berjumlah 4, bola voli berjumlah 4 , bola sepak berjumlah 3 , memiliki tongkat estafet berjumlah 4 , meteran berjumlah 1 , memiliki alat tolak peluru berjumlah 2 , lempar cakram berjumlah 2, lempar lembing berjumlah 3 , memiliki bola plastik berjumlah 20 , dan memiliki matras berjumlah 4 . Sekolah ini mempunyai prasarana atau luas tempat bermain dan berolahraga sebesar $360 \mathrm{~m}^{2}$.

\section{SMP Negeri 11 Pasuruan}

Sarana keseluruhan yang dimiliki oleh SMP Negeri 11 Pasuruan meliputi bola basket berjumlah 4, bola voli berjumlah 2, bola sepak berjumlah 1 , memiliki tongkat estafet berjumlah 6 , meteran berjumlah 1 , memiliki alat tolak peluru berjumlah 2, memiliki bola plastik berjumlah 2, memiliki matras berjumlah 1 , dan memiliki tape recorder berjumlah 1 . Sekolah ini mempunyai prasarana atau luas tempat bermain dan berolahraga sebesar $452 m^{2}$.

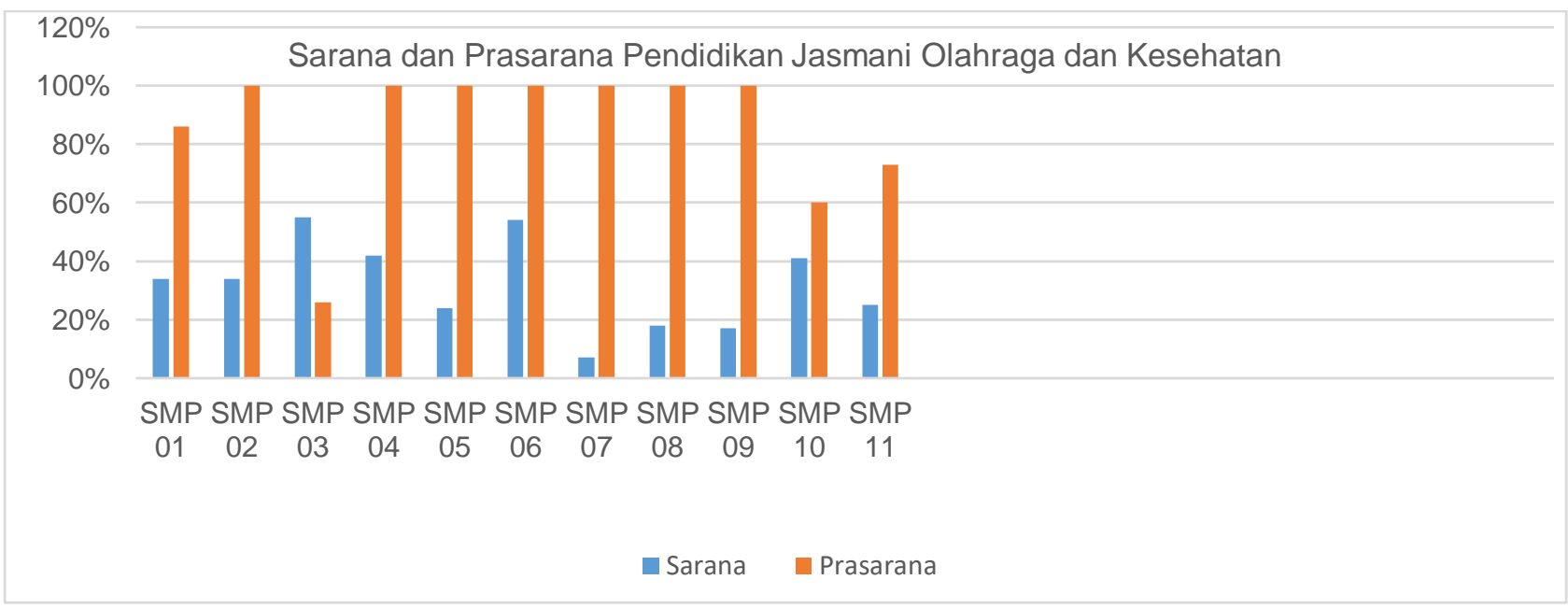

Gambar 1. Diagaram analisis data sarana dan prasarana Pendidikan Jasmani Olahraga dan Kesehatan di SMP Negeri se-Kota Pasuruan 


\section{PEMBAHASAN}

\section{Sarana}

Berdasarkan hasil penelitian, peneliti mendapat jumlah sarana pendidikan jasmani olahraga dan kesehatan di SMP Negeri se-Kota Pasuruan yaitu peralatan permainan bola besar seperti sarana bolabasket, sarana bolavoli, dan sarana sepakbola meliputi bola dengan total sarana keseluruhan persentase $83,84 \%$ dan masuk pada kategori layak. Adapun peralatan atletik meliputi tongkat estafet, meteran, tolak peluru, lempar cakram, dan lempar lembing memperoleh total sarana keseluruhan persentase $91,24 \%$ dan masuk pada kategori layak. Peralatan senam menggunakan alat meliputi bola plastik, tali loncat, tongkat senam, palang tunggal, gelang senam, serta simpai memperoleh total sarana keseluruhan persentase $28,28 \%$ dan masuk pada kategori kurang layak. Untuk peralatan senam lantai meliputi matras dan peti loncat memperoleh total sarana keseluruhan persentase yaitu $21,21 \%$ dan masuk pada kategori tidak layak. Peralatan aktivitas ritmik seperti tape recorder dan kaset senam memperoleh total sarana keseluruhan persentase yaitu $9,60 \%$ dan masuk pada kategori tidak layak.

Dikarenakan belum pernah dilakukan penelitian survei sarana dan prasarana penunjang mata pelajaran pendidikan jasmani olahraga dan kesehatan di daerah Kota Pasuruan, maka sebagai referensi peneliti membandingkan hasil penelitian dengan penelitian serupa pada obyek penelitian SMP Negeri 6 Sinjai Selatan Kab. Sinjai yang diteliti oleh (Krisnabayu, 2019), SMP Negeri 1 Pujananting Kab.Barru yang diteliti oleh (Hernawati, 2019), SMP Negeri 1 Tonra Kab. Bone yang diteliti oleh (Sudirman, 2019), Survei Sarana dan Prasarana Dalam Pembelajaran Penjasorkes di SMA/SMK/MA Kabupaten Buleleng yang diteliti oleh (Setyawan, 2015), dan Survei Sarana dan Prasarana Pendidikan Jasmani Olahraga dan Kesehatan SMA Negeri 2 Bantaeng oleh (Nursamsi, 2019) adalah sebagai berikut.

Berdasarkan hasil penelitian yang dilakukan oleh (Krisnabayu, 2019), disebutkan bahwa data sarana dan prasarana per cabang olahraga yaitu cabang olahraga senam secara keseluruhan sebesar $57,7 \%$, sarana dan prasarana olahraga atletik secara keseluruhan sebesar $43,1 \%$, sarana dan prasarana olahraga permainan bola besar secara keseluruhan sebesar $296,8 / 4=74,2 \%$, sarana dan prasarana olahraga permainan bola kecil secara keseluruhan sebesar 180/2 = 90 dan sarana prasarana olahraga bela diri secara keseluruhan sebesar $0 \%$. Hasil penelitian ini menunjukkan bahwa secara umum jumlah sarana dan prasarana pendidikan jasmani olahraga dan kesehatan di SMP Negeri 6 Sinjai Selatan sudah cukup ideal dengan persentase $52,96 \%$.

Berdasarkan hasil penelitian yang dilakukan oleh (Hernawati, 2019), dapat disimpulkan bahwa rata-rata sarana dan prasarana pada cabang olahraga senam adalah $83,33 \%$ dengan kategori "Sangat ideal", cabang olahraga atletik $37,5 \%$ dengan kategori "kurang ideal", cabang olahraga sepakbola 50\% dengan kategori "cukup ideal", cabang olahraga bolavoli $100 \%$ dengan kategori "Sangat ideal", cabang olahraga bolabasket $100 \%$ dengan kategori "Sangat ideal", cabang olahraga bulutangkis $100 \%$ dengan kategori "Sangat ideal", cabang olahraga sepak takraw $100 \%$ dengan kategori "Sangat ideal", dan cabang olahraga tenis meja $70 \%$ dengan kategori "ideal".

Pada penelitian yang dilakukan oleh (Sudirman, 2019), untuk menentukan kategori baik atau layak, cukup atau kurang dari jumlah bola yang di miliki sekolah perlu dihitung persentase dengan cara jumlah bola voli yang dimiliki dibagi dengan jumlah ideal dikalikan $100 \%$. Pembelajaran pendidikan jasmani olahraga dan kesehatan di SMP Negeri 1 Tonra Kab. Bone secara kategori termasuk ideal. 1 sarana atau 4\% yang termasuk kategori ideal, 7 sarana atau $28 \%$ yang termasuk kategori cukup ideal, 1 sarana yang termasuk kategori kurang ideal.

Berdasarkan hasil penelitian menunjukkan data yang diperoleh bahwa sarana dan prasarana di Kab. Buleleng masih kurang ideal. Hal ini dapat terlihat dari penggabungan jumlah persentase yang terlihat dimana "sangat kurang ideal" menunjukkan angka 742 yang menempati standar persentase 0-20\% disusul dengan angka 36 "kurang ideal" yang menempati standar persentase 21-40\%, "cukup ideal" dengan angka 153 yang menempati standar persentase $41-60 \%$, ideal dengan angka 10 yang menempati standar $61-80 \%$, dan sangat ideal dengan angka 409 yang menempati standar $81-100 \%$ (Setyawan, 2015).

Berdasarkan hasil penelitian yang dilakukan oleh (Nursamsi, 2019), disimpulkan bahwa hasil data penelitian menunjukkan keseluruhan sarana dan prasarana pembelajaran olahraga senam sebesar 33,3\%, pembelajaran olahraga atletik sebesar $175 \%$, pembelajaran olahraga permainan $56,5 \%$, pembelajaran 
olahraga bela diri sebesar $0 \%$ dan setelah dijumlahkan keseluruhan persentase sarana dan prasarana kemudian dibagi dengan jumlah cabang olahraga maka ditemukan hasil persentase sebesar $66,2 \%$ dengan kategori layak.

Jadi dapat disimpulkan dari penelitian yang sudah diteliti oleh peneliti bahwa hasil penelitian sarana pendidikan jasmani olahraga dan kesehatan di tingkat SMP Negeri se-Kota Pasuruan dikatakan "Tidak Layak".

\section{Prasarana}

Berdasarkan hasil penelitian, peneliti mendapat jumlah prasarana pendidikan jasmani olahraga dan kesehatan di SMP Negeri se-Kota Pasuruan yaitu SMP Negeri 1 mendapatkan kategori kriteria tidak layak, SMP Negeri 2 mendapatkan kategori kriteria layak, SMP Negeri 3 mendapatkan kategori kriteria tidak layak, SMP Negeri 4 mendapatkan kategori kriteria layak, SMP Negeri 5 mendapatkan kategori kriteria layak, SMP Negeri 6 mendapatkan kategori kriteria layak, SMP Negeri 7 mendapatkan kategori kriteria layak, prasarana yang ada di SMP Negeri 8 dikatakan layak, prasarana yang ada di SMP Negeri 9 dikatakan layak, adapun prasarana di SMP Negeri 10 dikatakan tidak layak demikian juga dengan SMP Negeri 11 mendapatkan kategori kriteria tidak layak. Dari keseluruahan prasarana yang layak sebanyak 7 SMP $(63,64 \%)$ yaitu SMP Negeri 2 , SMP Negeri 4, SMP Negeri 5, SMP Negeri 6, SMP Negeri 7, SMP Negeri 8, dan SMP Negeri 9, untuk yang tidak layak sebanyak 4 SMP $(36,36 \%)$.

Dikarenakan belum pernah dilakukan penelitian survei sarana dan prasarana penunjang mata pelajaran pendidikan jasmani olahraga dan kesehatan di daerah Kota Pasuruan, maka sebagai referensi peneliti membandingkan hasil penelitian dengan penelitian serupa pada obyek penelitian di SMP Negeri se-Kota Purbalingga yang diteliti oleh (Pratomo, 2012), SMP Negeri 13 Makasar yang diteliti oleh (Zulkifli, 2018), Mts se-Kecamatan Klojen Kota Malang oleh (Khikmah, 2017), Survei Sarana dan Prasarana Pendidikan Jasmani dan Olahraga di SMA Negeri 2 Camba Kab. Maros yang diteliti oleh (Irwandi, 2019), serta Survei Sarana dan Prasarana Pendidikan Jasmani Olahraga dan Kesehatan SMA Negeri 1 Takalar oleh (Amirah, 2019) adalah sebagai berikut.

Berdasarkan penelitian yang sudah dilakukan di SMP Negeri se-Kota Purbalingga untuk rerata persentase sarana dan prasarana cabang atletik sebesar $51,96 \%$ atau dalam kategori cukup ideal, untuk rerata persentase sarana dan prasarana cabang olahraga permainan sebesar $59,02 \%$ atau dalam kategori cukup ideal, untuk rerata persentase sarana dan prasarana cabang aktivitas ritmik sebesar 56,96\% atau dalam kategori cukup ideal, untuk rerata persentase sarana dan prasarana pembelajaran pendidikan jasmani olahraga dan kesehatan di SMP Negeri se-Kota Purbalingga tahun 2012 yaitu sebesar $55,98 \%$. Untuk rincian kondisi sarana dan prasarana olahraga yaitu rerata persentase sarana dan prasarana di SMP Negeri 1 Purbalingga sebesar $100 \%$ dalam kategori sangat ideal, SMP Negeri 2 Purbalingga rerata persentase sarana dan prasarana sebesar $90 \%$ dalam kategori sangat ideal, SMP Negeri 3 Purbalingga rerata persentase sarana dan prasarana sebesar $70 \%$ dalam kategori ideal, SMP Negeri 4 Purbalingga rerata persentase sarana dan prasarana sebesar $100 \%$ dalam kategori sangat ideal, SMP Negeri 5 Purbalingga rerata persentase sarana dan prasarana sebesar 70\% dalam kategori ideal, dan SMP Negeri 6 Purbalingga rerata persentase sarana dan prasarana sebesar $86 \%$ dalam kategori sangat ideal (Pratomo, 2012).

Berdasarkan penelitian yang sudah dilakukan oleh (Zulkifli, 2018), menunjukkan hasil persentase rata-rata keseluruhan sarana dan prasarana keseluruhan dikatakan mendukung pembelajaran penjasorkes di SMP Negeri 13 Makasar dengan perolehan 70,79\% dikategorikan "baik". Persentase kepemilikan prasarana berupa lapangan dimana dari 8 prasarana, sudah tersedia 4 prasarana atau 50\% yang tergolong sangat baik, dan 2 prasarana atau $25 \%$ tergolong sedang dan terdapat 2 jenis prasarana yang jumlah kuantitasnya termasuk dalam kategori sangat kurang atau $0 \%$.

Berdasarkan hasil penelitian yang dilakukan oleh (Khikmah, 2017), menunjukkan bahwa sarana dan prasarana pembelajaran pendidikan jasmani di MTs se-Kecamatan Klojen Kota Malang yaitu MTsN Malang 1 dengan persentase $65 \%$ mendapat kriteria cukup baik dan layak, MTs Attaraqqie dengan persentase $30 \%$ mendapat kriteria tidak baik dan layak, MTs Khadijah dengan persentase $50 \%$ mendapat kriteria kurang baik dan layak, MTs Mu'allimin NU dengan persentase 38\%, dan MTs Mu'allimin NU dengan persentase 7\% mendapat kriteria tidak baik dan tidak layak. Prasarana yang harus ada adalah $2700 \mathrm{~m}^{2}$ sedangkan MTsN 1 Malang hanya memiliki $2265,8 \mathrm{~m}^{2}$, Prasarana keseluruhan yang harus ada adalah $2000 \mathrm{~m}^{2}$ sedangkan MTs Attaraqqie hanya memiliki $90 \mathrm{~m}^{2}$ yaitu kurang dari $2000 \mathrm{~m}^{2}$, prasarana keseluruhan yang harus ada adalah $1400 \mathrm{~m}^{2}$ sedangkan di MTs Khadijah memiliki luas keseluruhan $1539 \mathrm{~m}^{2}$, prasarana yang harus ada adalah 
$1000 \mathrm{~m}^{2}$ sedangkan di MTs Mu'allimin NU memiliki $1661 \mathrm{~m}^{2}$, dan prasarana yang harus ada adalah $135 \mathrm{~m}^{2}$ sedangkan di MTs Mu'allimat memiliki keseluruhan luas $450 \mathrm{~m}^{2}$.

Sarana dan prasarana olahraga senam pada SMA Negeri 2 Camba Kab. Maros dalam kategori kurang dilihat dari keterbatasa sarana yang dimiliki. Sementara dalam bidang prasarana telah memiliki aula. Sarana dan prasarana dalam olahraga atletik dan tenis meja pada SMA ini juga masih tergolong dalam kategori cukup. Adanya keterbatasan untuk jumlah standar minimum yang dibutuhkan dalam pembelajaran pendidikan jasmani olahraga dan kesehatan. Adapun sarana dan prasarana olahraga pada olahraga sepakbola, sepak takraw, bolavoli, bolabasket, bulutangkis, tergolong dalam kategori baik. Berdasarkan hasil uraian di atas menunjukkan bahwa dari sembilan cabang olahraga yang diteliti di SMA Negeri 2 Camba Kab. Maros, semua cabang olahraga masih dalam kategori cukup dalam ketersediaan sarana dan prasarana olahraga yang memiliki kategori baik sekali (Irwandi, 2019).

Berdasarkan hasil penelitian yang dilakukan oleh (Amirah, 2019), rata-rata sarana dan prasarana pada pembelajaran olahraga senam 37,5\% cukup, cabang pembelajaran atletik 43,75\% kategori cukup, pembelajaran olahraga sepakbola $16,66 \%$ dalam kategori kurang, pembelajaran olahraga sepak takraw $81,25 \%$ kategori baik, pembelajaran olahraga bolabasket $91,66 \%$ dengan kategori baik, dan pembelajaran olahraga tenis meja $50 \%$ dengan kategori cukup. Selanjutnya menentukan rata-rata sarana dan prasarana yang mendukung pembelajaran penjas di SMA Negeri 1 Takalar yaitu sebesar $60,11 \%$ kategori cukup untuk mendukung proses pembelajaran pendidikan jasmani.

Jadi dapat disimpulkan dari penelitian yang sudah diteliti oleh peneliti bahwa hasil penelitian sarana pendidikan jasmani olahraga dan kesehatan di tingkat SMP Negeri se-Kota Pasuruan dikatakan "Layak".

\section{KESIMPULAN}

Berdasarkan hasil dan pembahasan yang peneliti deskripsikan untuk sarana keseluruhan di tingkat SMP Negeri se-Kota Pasuruan mendapat kriteria Tidak Layak, sedangkan untuk prasarana keseluruhan SMP Negeri se-Kota Pasuruan mendapatkan kriteria Layak.meski jika ditinjau kembali per sekolah ada beberapa sekolah yang sudah memenuhi kriteria standar minimal dari Permendiknas.

\section{DAFTAR PUSTAKA}

Adi, S., \& Fathoni, A. F. (2019). Development of Learning Model Based on Blended Learning in Sports School. https://doi.org/10.2991/acpes-19.2019.2

Adi, S., \& Fathoni, A. F. (2020a). Blended Learning Analysis for Sports Schools in Indonesia. International Journal of Interactive Mobile Technologies (IJIM), 14(12), 149-164. Retrieved from https://www.onlinejournals.org/index.php/i-jim/index

Adi, S., \& Fathoni, A. F. (2020b). The effectiveness and efficiency of blended learning at sport schools in Indonesia. International Journal of Innovation, Creativity and Change.

Adiningtyas, W. P., Tomi, A., \& Yudasmara, D. S. (2020). Survei Pembinaan Ekstrakurikuler Bolabasket pada Peserta Didik Sekolah Menengah Atas. Sport Science and Health, 2(1), 32-38. Retrieved from http://journal2.um.ac.id/index.php/jik/article/view/11129/5120

Asseffa, N. A., Bukola, F., \& Ayodele, A. (2016). Determinants of use of health facility for childbirth in rural Hadiya zone, Southern Ethiopia. BMC Pregnancy and Childbirth. https://doi.org/10.1186/s12884-016$1151-1$

Dawud, V. W. G. W. A. N., \& Hariyanto, E. (2020). Survei Kondisi Fisik Pemain Sepakbola U 17. Sport Science and Health, 2(4), 224-231. Retrieved from http://journal2.um.ac.id/index.php/jfik/index

Efendi, F., Ni'Mah, A. R., Hadisuyatmana, S., Kuswanto, H., Lindayani, L., \& Berliana, S. M. (2019). Determinants of facility-based childbirth in Indonesia. Scientific World Journal. https://doi.org/10.1155/2019/9694602

Fathoni, A. F. (2018). The Role of Blended Learning on Cognitive Step in Education of Sport Teaching by Adjusting the Learning Style of the Students. https://doi.org/10.2991/isphe-18.2018.49 
Fathoni, \& Fajar, A. (2017). Pengembangan Rubrik Penilaian Keterampilan Mata Pelajaran PJOK Materi Bola Besar dan Kecil Kelas VII Semester Genap. DISERTASI Dan TESIS Program Pascasarjana UM.

Ichsan, I. Z., \& Mulyani, S. W. W. (2018). Improving students' motoric skills through demonstration method in recycling plastic waste. Jurnal Pendidikan Biologi Indonesia. https://doi.org/10.22219/jpbi.v4i2.5890

Irwandi. 2019. Survei Sarana dan Prasarana Pendidikan Jasmani dan Olahraga di SMA Negeri 2 Camba Kabupaten Maros. Makassar: Fakultas Ilmu Keolahragaan Universitas Negeri Makassar.

Kafle, N. P. (2013). Hermeneutic phenomenological research method simplified. Bodhi: An Interdisciplinary Journal. https://doi.org/10.3126/bodhi.v5i1.8053

Kementerian Pendidikan Republik Indonesia. 2017. Peraturan Menteri Pendidikan Nasional Republik Indonesia Nomor 19 Tahun 2017 tentang Pengelolaan Standar Pendidikan oleh Satuan Pendidikan Dasar dan Menengah. Jakarta: Kemendiknas.

Kementerian Pendidikan Republik Indonesia. 2007. Peratuan Menteri Pendidikan Nasional Republik Indonesia Nomor 24 Tahun 2007 tentang Standar Sarana dan Prasarana Untuk Sekolah Dasar/Madrasah Ibtidaiyah (SD/MI), Sekolah Menengah Pertama/Madrasah Tsanawiyah (SMP/MTs), Dan Sekolah Menengah Atas/Madrasah Aliyah (SMA/MA). Jakarta: Kemendiknas.

Kunlasomboon, N., Wongwanich, S., \& Suwanmonkha, S. (2015). Research and Development of Classroom Action Research Process to Enhance School Learning. Procedia - Social and Behavioral Sciences. https://doi.org/10.1016/j.sbspro.2015.01.248

Khikmah. Akhidatul. 2017. Survei Sarana dan Prasarana Pendidikan Jasmani di Madrasah Tsanawiyah (MTs) Se-Kecamatan Klojen Kota Malang. Malang: Fakultas IImu Keolahragaan Universitas Negeri Malang.

Krisnabayu, Adhytia. 2019. Survei Sarana dan Prasarana Pendidikan Jasmani Olahraga dan Kesehatan SMP Negeri 6 Sinjai Selatan Kabupaten Sinjai. Makassar: Fakultas IImu Keolahragaan Universitas Negeri Makassar.

Litardiansyah, B. A., \& Hariyanto, E. (2020). Survei Kondisi Fisik Peserta Ekstrakurikuler Futsal Putra dan Putri Sekolah Menengah Atas. Sport Science and Health, 2(6), 331-339. Retrieved from http://journal2.um.ac.id/index.php/jfik/article/view/14090/5925

McCusker, K., \& Gunaydin, S. (2015). Research using qualitative, quantitative or mixed methods and choice based on the research. Perfusion (United Kingdom). https://doi.org/10.1177/0267659114559116

Napitupulu, D., Rahim, R., Abdullah, D., Setiawan, M. I., Abdillah, L. A., Ahmar, A. S., .. Pranolo, A. (2018). Analysis of Student Satisfaction Toward Quality of Service Facility. Journal of Physics: Conference Series. https://doi.org/10.1088/1742-6596/954/1/012019

Nursamsi. 2019. Survei Sarana dan Prasarana Pendidikan Jasmani dan Olahraga SMA Negeri 2 Bantaeng. Makassar: Fakultas IImu Keolahragaan Universitas Negeri Makassar.

Pratomo, A. T. 2012. Survei Sarana dan Prasarana Pembelajaran Pendidikan Jasmani Olahraga dan Kesehatan Pada SMP Negeri Se-Kota Purbalingga. Semarang: Fakultas IImu Keolahragaan Universitas Negeri Semarang, 2 (6): 373-375.

Sudirman. 2019. Survei Ketersediaan dan Kelayakan Sarana dan Prasarana Penjasorkes Pada SMP Negeri 1 Tonra Kabupaten Bone. Makassar: Faklutas IImu Keolahragaan Universitas Negeri Makassar.

Zulfa, I. I., \& Kurniawan, A. W. (2020). Survei Kebugaran Jasmani Kelas VIII SMP Plus Asy-Syukur Kanigoro. Sport Science and Health, 1(3), 184-192. Retrieved from http://journal2.um.ac.id/index.php/jfik/article/view/11343/4918

Zulkifli. 2018. Survei Sarana dan Prasarana Olahraga SMP Negeri 13 Makassar. Makassar: Jurusan Pendidikan Jasmani Kesehatan dan Rekreasi Universitas Negeri Makassar. 